\title{
Aerosolized Perfluorocarbon Suppresses Early Pulmonary Inflammatory Response in a Surfactant-Depleted Piglet Model
}

\author{
KATHARINA VON DER HARDT, ELLEN SCHOOF, MICHAEL A. KANDLER, \\ JÖRG DÖTSCH, AND WOLFGANG RASCHER \\ Klinik für Kinder und Jugendliche der Friedrich-Alexander-Universität Erlangen-Nürnberg, D-91054 \\ Erlangen, Germany
}

\begin{abstract}
The effect of new ventilation strategies on initial pulmonary inflammatory reaction was studied in a surfactant-depleted piglet model. Sixty minutes after induction of lung injury by bronchoalveolar lavage, piglets received either aerosolized FC77 (aerosol$\mathrm{PFC}, 10 \mathrm{~mL} / \mathrm{kg} / \mathrm{h}, n=5$ ) or partial liquid ventilation (PLV) with FC77 at functional residual capacity volume (FRC-PLV, 30 $\mathrm{mL} / \mathrm{kg}, n=5$ ), or at low volume (LV-PLV, $10 \mathrm{~mL} / \mathrm{kg}$ per hour, $n=5$ ), or intermittent mandatory ventilation (control, $n=5$ ). After $2 \mathrm{~h}$, perfluorocarbon application was stopped and intermittent mandatory ventilation continued for $6 \mathrm{~h}$. After a total experimental period of $8 \mathrm{~h}$, animals were killed and lung tissue obtained. mRNA expression of IL- $1 \beta$, IL- 6 , IL- 8 , and TGF- $\beta$ in porcine lung tissue was quantified using TaqMan real-time PCR and normalized to $\beta$-actin (A) and hypoxanthine-guaninephosphoribosyl-transferase $(\mathrm{H})$. In the aerosol-PFC group, IL$1 \beta$, IL-6, IL-8, and transforming growth factor (TGF)- $\beta$ mRNA expression in lung tissue was significantly lower than in the control group. Reduction was $95 \%$ for IL-1 $\beta / \mathrm{H}(p<0.001), 73 \%$ for IL-6/H $(p<0.05), 87 \%$ for IL-8/H $(p<0.001)$, and $38 \%$ for TGF- $\beta / \mathrm{H}(p<0.01)$. A lower mRNA gene expression was also determined for IL- $1 \beta$ and IL- 8 when the aerosol-PFC group was
\end{abstract}

\section{ABSTRACT}

compared with the LV-PLV group $[91 \%$ for IL- $1 \beta / \mathrm{H}(p<$ $0.001), 75 \%$ for IL-8/H $(p<0.001)]$. In the FRC-PLV group, mRNA expression of IL- $1 \beta$ was significantly lower than in the control $(p<0.05)$ and LV-PLV $(p<0.01)$ group. In a surfactant-depleted piglet model, aerosol therapy with perfluorocarbon but not LV-PLV reduces the initial pulmonary inflammatory reaction at least as potently as PLV at FRC volume. (Pediatr Res 51: 177-182, 2002)

A, $\beta$-actin
BPD, bronchopulmonary dysplasia
FIO $_{2}$, inspiratory fraction of oxygen
FRC, functional residual capacity
H, hypoxanthine-guanine-phosphoribosyl-transferase
IMV, intermittent mandatory ventilation
LV, low volume
PFC, perfluorocarbon
PLV, partial liquid ventilation
RU, relative units

In spite of considerable progress in neonatal respiratory management, morbidity and mortality due to BPD resulting from long-term and intensive respiratory support is still a major problem. Barotrauma, volutrauma, oxygen toxicity, and pulmonary infections are crucial factors contributing to the development of BPD. The initial acute pulmonary inflammatory response induces a complex process finally leading to irreversible lung damage and fibrosis (1). In the complex network of inflammatory mechanisms, intrapulmonary elevation of neutrophils and macrophages were observed and several mediators

Received September 13, 2000; accepted June 15, 2001.

Correspondence and reprint requests: Prof. Dr. med. W. Rascher, Klinik mit Poliklinik für Kinder und Jugendliche, Loschgestr. 15, D-91054 Erlangen, Germany; e-mail: Wolfgang.Rascher@rzmail.uni-erlangen.de

The study was supported by a grant of the IZKF (Interdisziplinäres Zentrum für Klinische Forschung), University of Erlangen-Nürnberg, Germany. of inflammation have been identified $(1,2)$. Among others, proinflammatory cytokines such as IL- $1 \beta$ and IL-6, chemoattractant proteins such as IL- 8 , and fibrogenetic proteins such as transforming growth factor (TGF)- $\beta$ were found to be elevated early in the bronchoalveolar lavage fluid of infants developing $\operatorname{BPD}(1,2)$.

To improve oxygenation and ventilation in preterm neonates or neonates with severe lung disease, respiratory strategies as high-frequency oscillation ventilation (3-5) and therapy with inhaled nitric oxide (6) have been developed.

PLV is another approach to improve oxygenation, ventilation, lung mechanics, and histologic changes in critically impaired lungs (7-12). PFCs are excellent solvents for carbon dioxide and oxygen and disperse easily because of their high spreading coefficient, recruiting collapsed alveoli. In "conventional" PLV, PFC is instilled into the lung at FRC volume and 
ventilation is performed with a conventional respirator. Clinical trials conducting PLV with perfluorooctylbromide (Liquivent, Alliance, San Diego, CA, U.S.A.) have been performed in adult patients with acute respiratory distress syndrome (ARDS) (13) and in neonates (14) without significant side effects. However, data confirming the long-term clinical benefit of PLV are still inconclusive. A recently conducted study in adult patients with ARDS did not show an additional benefit of PLV to a lung protective way of conventional ventilation (15).

A first hint of possible anti-inflammatory effects of PLV is that intrapulmonary accumulation of neutrophil granulocytes was shown to be reduced by PLV in rabbits (16) and rats (17). Perfluorooctylbromide reduced the in vitro activity of rabbit and piglet alveolar macrophages to produce reactive oxygen species (18).

The objective of the present study was to evaluate the effect of different ventilatory strategies in a surfactant-depleted piglet model on the development of the initial acute pulmonary inflammatory reaction preceding BPD. The hypothesis was to prove whether aerosolized PFC, LV-PLV, or liquid ventilation at FRC volume would reduce the early pulmonary inflammatory reaction compared with conventional IMV. An additional goal was to see whether differences in early pulmonary inflammatory reaction could be detected at the mRNA level by determining gene expression of proinflammatory cytokines (IL-1 $\beta$, IL-6, IL-8, and TGF- $\beta$ ) in lung tissue.

\section{MATERIALS AND METHODS}

Subjects. Twenty piglets with a body weight of $4.01 \pm 0.35$ $\mathrm{kg}$ were included in the study. Data from 18 piglets were available for evaluation. Two piglets were excluded because of early death by pneumothorax in one piglet in the LV-PLV group and poor mRNA quality with degradation in one piglet of the control group. The animal experiments were approved by the Animal Care Committee of the university and the government of Mittelfranken, Germany, and performed according to the guidelines of the National Institutes of Health.

Protocol. The piglets were transported from the breeder to the laboratory immediately before the experiment started. They received $2 \mathrm{mg} / \mathrm{kg}$ azaperone i.m. for sedation before transport. On arrival at the laboratory, they received $1 \mathrm{mg} / \mathrm{kg}$ azaperone and $0.5 \mathrm{mg} / \mathrm{kg}$ midazolam i.m. After a venous catheter had been placed into an ear vein, anesthesia was induced with midazolam $(1 \mathrm{mg} / \mathrm{kg})$, fentanyl $(2.5 \mu \mathrm{g} / \mathrm{kg})$, and ketamine (5 $\mathrm{mg} / \mathrm{kg}$ ) followed by continuous infusion of midazolam (1.5 $\mathrm{mg} / \mathrm{kg} / \mathrm{h})$, fentanyl $(0.01 \mathrm{mg} / \mathrm{kg} / \mathrm{h})$, and ketamine $(15 \mathrm{mg} / \mathrm{kg} / \mathrm{h})$. After tracheotomy, paralysis was induced with vecuronium 0.2 $\mathrm{mg} / \mathrm{kg}$ i.v. and maintained with vecuronium $0.2 \mathrm{mg} / \mathrm{kg} / \mathrm{h}$. A sheath (4.5-Fr, check-flo performer introducer set, Cook, Mönchengladbach, Germany) was placed into the right jugular vein and a thermodilution catheter (4-Fr, Arrow, Erding, Germany) into the pulmonary artery. After preparation of the left femoral artery, an arterial catheter (20 G, Arrow) was placed and a sensor for online blood gas monitoring (Paratrend 7, Agilent, Böblingen, Germany) was inserted. The piglets received a transcutaneous urinary catheter (Cystofix minipäd, Braun, Melsungen, Germany) and a gastric tube. IMV was performed with a time-cycled, pressure controlled neonatal respirator (Infant Star 950, Mallinckrodt, Hennef, Germany) starting with a peak inspiratory pressure (PIP) of $20 \mathrm{~cm} \mathrm{H}_{2} \mathrm{O}$, a positive end-expiratory pressure (PEEP) of $4 \mathrm{~cm} \mathrm{H}_{2} \mathrm{O}$, an $\mathrm{FIO}_{2}$ of 1 , and a frequency of 40 breaths/min, augmented to 50 breaths/min before lavage. Respiratory gas was humidified and temperature was kept at $39^{\circ} \mathrm{C}$ (MR 700 AGM Fisher \& Paykel, Welzheim, Germany). Lung injury was induced by repeated saline lung lavage (19) $\left(\mathrm{NaCl} 0.9 \%\right.$ at $\left.39^{\circ} \mathrm{C}\right)$ using $30 \mathrm{~mL} / \mathrm{kg}$ per side. Lung injury was considered successful when the arterial $\mathrm{PaO}_{2}$ remained below $80 \mathrm{~mm} \mathrm{Hg}$ for a period of $60 \mathrm{~min}$. During lavage, PIP and PEEP were increased to 32 and $8 \mathrm{~cm}$ $\mathrm{H}_{2} \mathrm{O}$, respectively.

The animals were randomized to four different therapy groups (aerosol-PFC, FRC-PLV, LV-PLV, and control). In all animals, respiratory support was held constant at identical respiratory settings (PEEP $8 \mathrm{~cm} \mathrm{H}_{2} \mathrm{O}$, PIP $32 \mathrm{~cm} \mathrm{H}_{2} \mathrm{O}, \mathrm{FIO}_{2} 1.0$, 50 breaths $/ \mathrm{min}$ ). Piglets in the aerosol-PFC group received 10 $\mathrm{mL} / \mathrm{kg} / \mathrm{h}$ PFC (FC77, 3M, Neuss, Germany) aerosolized by an aerosolization catheter (Trudell Medical, Toronto, Canada) (20) at the distal end of the endotracheal tube for $2 \mathrm{~h}$. Piglets in the LV-PLV group received PFC at a dose of $10 \mathrm{~mL} / \mathrm{kg} / \mathrm{h}$, administered endotracheally through the side port of the tube connector for $2 \mathrm{~h}$. In the FRC-PLV group, $30 \mathrm{~mL} / \mathrm{kg}$ FC77 were filled into the lung via a side port of the tube connector over a period of $30 \mathrm{~min}$. The evaporative loss of FC77 in the FRC-PLV group was estimated to be $20 \mathrm{~mL} / \mathrm{kg} / \mathrm{h}$. Therefore, a continuous replacement of FC77 $(20 \mathrm{~mL} / \mathrm{kg}$ per hour $)$ was performed in the FRC-PLV group. Therapy with FC77 was stopped after $2 \mathrm{~h}$. After an additional observation period of $6 \mathrm{~h}$ ( $8 \mathrm{~h}$ after establishment of lung injury) with constant respiratory parameters, animals were killed with $50 \mathrm{mg} / \mathrm{kg}$ methohexital and $20 \mathrm{~mL}$ potassium chloride. The trachea was clamped at a PEEP of $8 \mathrm{~cm} \mathrm{H}_{2} \mathrm{O}$ and lungs and heart were removed en bloc. Anterior and posterior tissue specimens were taken from the right lung. Samples from the anterior part of the superior and middle lobes were defined as samples from nondependent pulmonary areas. Samples from the posterior part of the inferior lobe were defined as samples from dependent pulmonary areas. As the inferior lobe was larger than the superior and middle lobes, four tissue specimens were taken from the inferior lobe (central and basal), two from the superior, and two from the middle lobe. Samples were frozen in liquid nitrogen and kept at $-80^{\circ} \mathrm{C}$ for up to 8 wk until analysis.

Measurements. mRNA expression of IL-1 $\beta$, IL-6, IL-8, and TGF- $\beta$ was determined by TaqMan real-time PCR. To normalize gene expression, mRNA expression of the housekeeping genes $\beta$-actin (A) and hypoxanthine-guanine-phosphoribosyl-transferase $(\mathrm{H})$ was measured.

RNA extraction and reverse transcription. Total RNA was extracted from the tissue using guanidine-thiocyanate acid phenol (RNAzol, WAK Chemie, Medical GmbH, Bad Homburg, Germany). The RNA concentration was determined spectrophotometrically. One microgram of RNA was reverse transcribed in a volume of $20 \mu \mathrm{L}$ at $39^{\circ} \mathrm{C}$ for $60 \mathrm{~min}$ (all chemicals were obtained from Roche Molecular Biochemicals, Mannheim, Germany). 
TaqMan real-time PCR. Efficiency and reliability of this method have been shown earlier $(21,22)$. The approach for measurement of gene expression by TaqMan real-time PCR is based upon the $5^{\prime}$ exonuclease activity of the Taq polymerase. Within the amplicon defined by a gene-specific oligonucleotide primer pair, an oligonucleotide probe labeled with two fluorescent dyes is designed. As long as the probe is intact, the emission of a reporter dye (i.e. 6-carboxy-fluorescein, FAM) at the $5^{\prime}$ end is quenched by the second fluorescent dye (6carboxy-tetramethyl-rhodamine, TAMRA) at the 3 ' end. During the extension phase of the PCR, the Taq polymerase cleaves the probe releasing the reporter dye. An automated photometric detector combined with a special software (ABI Prism 7700 Sequence Detection System, PerkinElmer, Foster City, CA, U.S.A.) monitors the increasing reporter dye emission. The algorithm normalizes the signal to an internal reference $(\Delta R n)$ and calculates the threshold cycle number $\left(C_{T}\right)$ when the $\Delta \mathrm{Rn}$ reaches 10 times the $\mathrm{SD}$ of the baseline. The $\mathrm{C}_{\mathrm{T}}$ values of the probes are interpolated to an external reference curve constructed by plotting the relative amounts of a serial dilution of a known template versus the corresponding $\mathrm{C}_{\mathrm{T}}$ values. Commercial reagents (TaqMan PCR Reagent Kit, PerkinElmer) and conditions according to the manufacturer's protocol were used. To $25 \mu \mathrm{L}$ reaction mix, $2.5 \mu \mathrm{L}$ of cDNA (reverse transcription mixture) and oligonucleotides with a final concentration of $300 \mathrm{nM}$ of primers and $200 \mathrm{nM}$ of TaqMan hybridization probe were added. The oligonucleotides of each target of interest were designed by the Primer Express software (PerkinElmer) using uniform selection parameters that allowed the application of the same cycle conditions confirmed by primer optimization. Primers and probes were purchased from Eurogentec (Seraing, Belgium). The thermocycler parameters were $50^{\circ} \mathrm{C}$ for $2 \mathrm{~min}, 95^{\circ} \mathrm{C}$ for $10 \mathrm{~min}$ followed by 40 cycles of $95^{\circ} \mathrm{C}$ for $15 \mathrm{~s}$ and $60^{\circ} \mathrm{C}$ for $1 \mathrm{~min}$. Serial dilutions of one of the samples served as reference providing relative quantification of the unknown samples. Gene expression was related to the housekeeping genes $\beta$-actin (A) and hypoxanthine-guanine-phosphoribosyl-transferase (H).

The following primers and TaqMan probes were used:

Hypoxanthine-guanine-phosphoribosyl-transferase:

Forward: 5'-TGGAAAGAATGTCTTGATTGTTGAAG-3'

Reverse: 5'-ATCTTTGGATTATGCTGCTTGACC-3'

TaqMan probe: 5' (FAM)-ACACTGGCAAAACAATGCAAACCTTGCT-(TAMRA) 3'

$\beta$-Actin:

Forward: 5'-TCATCACCATCGGCAACG-3'

Reverse: 5'-TTCCTGATGTCCACGTCGC-3'

TaqMan probe: 5' (FAM)-CCTTCCTGGGCATGGAGTCCTGC-(TAMRA) 3'

IL-1 $\beta$ :

Forward: 5'-GGTTTCTGAAGCAGCCATGG-3'

Reverse: 5'-GATTTGCAGCTGGATGCTCC-3'

TaqMan probe: 5' (FAM)-AAAGAGATGAAGTGCTGCACCCAAAACCTG-(TAMRA)3'

IL-6:

Forward: 5'-GGGTAGGGAAGGCAGTAGCC-3'

Reverse: 5'-GAACTCCCTCTCCACAAGCG-3'
TaqMan probe: 5' (FAM)-CTTCAGTCCAGTCGCCTTCTCCCTGG-(TAMRA) 3'

IL-8:

Forward: 5'-TTCTGCAGCTCTCTGTGAGGC-3'

Reverse: 5'-GGTGGAAAGGTGTGGAATGC-3'

TaqMan probe: 5' (FAM)-TTCTGGCAAGAGTAAGTGCAGAACTTCGATG-(TAMRA)3'

TGF- $\beta$ :

Forward: 5'-TACGCCAAGGAGGTCACCC-3'

Reverse: 5'-CAGCTCTGCCCGAGAGAGC-3'

TaqMan probe: 5' (FAM)-CTAATGGTGGAAAGCGGCAACCAAATCTA-(TAMRA)3'

Data analysis. Data analysis was performed with Microsoft ACCESS, Microsoft EXCEL, and Graph Pad PRISM. Values are expressed as mean \pm SEM. Depending on the presence of Gaussian distribution, either the ANOVA or Kruskal-Wallis test were used for comparison of the groups. In case of significance, Bonferroni and Dunn's posthoc tests were applied, respectively. A $p$ value of $<0.05$ was considered significant. A difference between the groups was only considered as significant, if a $p$ value of $<0.05$ was found for normalization to both housekeeping genes.

\section{RESULTS}

Tissue samples from different lung lobes showed a significantly lower expression of IL- $1 \beta$ mRNA in the aerosol-PFC and FRC-PLV group than in the LV-PLV and control group. Compared with the control group, mRNA expression of IL $1 \beta / A$ was reduced by $91 \%$ in the aerosol-PFC group and by $86 \%$ in the FRC-PLV group $(p<0.001)$. Also, IL- 8 mRNA expression was significantly decreased in the aerosol-PFC group compared with the LV-PLV and control group. Reduction of IL-8/A mRNA expression in the aerosol-PFC group compared with the control group was $65 \%(p<0.001)$. In the aerosol-PFC group, IL-6 and TGF- $\beta$ mRNA expression were also significantly lower than in the control group. The reduction was $55 \%$ for IL-6/A $(p<0.05)$ and $27 \%$ for TGF- $\beta / \mathrm{A}(p$ $<0.05)$.

In the FRC-PLV group, the reduction of IL-6, IL-8, and TGF- $\beta$ mRNA expression was significant only when normalized to $\beta$-actin: IL-6 67\% $(p<0.05)$, IL-8 67\% $(p<0.01)$, and TGF- $\beta 30 \%(p<0.001)$. Details are shown in Table 1 .

Separate analysis of the lobes revealed the most pronounced differences in mRNA expression in the inferior lobe (Fig. 1, $A-D$ ). Details are shown in Tables 2, 3, and 4 .

Cytokine mRNA expression in the dependent pulmonary regions (posterior inferior lobe and posterior basal inferior lobe) was higher than in the nondependent pulmonary regions (anterior superior lobe and anterior middle lobe), but these data did not reach statistical significance. However, the differences in mRNA expression between the dependent and nondependent areas were reduced significantly in the aerosol group and not quite significantly in the FRC-PLV group.

Comparison of the mRNA expression for IL- $1 \beta$, IL-6, and IL-8 between the different lung lobes (superior, middle, and inferior) within each therapy group showed no significant difference when normalized to both housekeeping genes. How- 
Table 1. Cytokine $m R N A$ expression (mean \pm SEM; relative units) in lung tissue (all lobes)

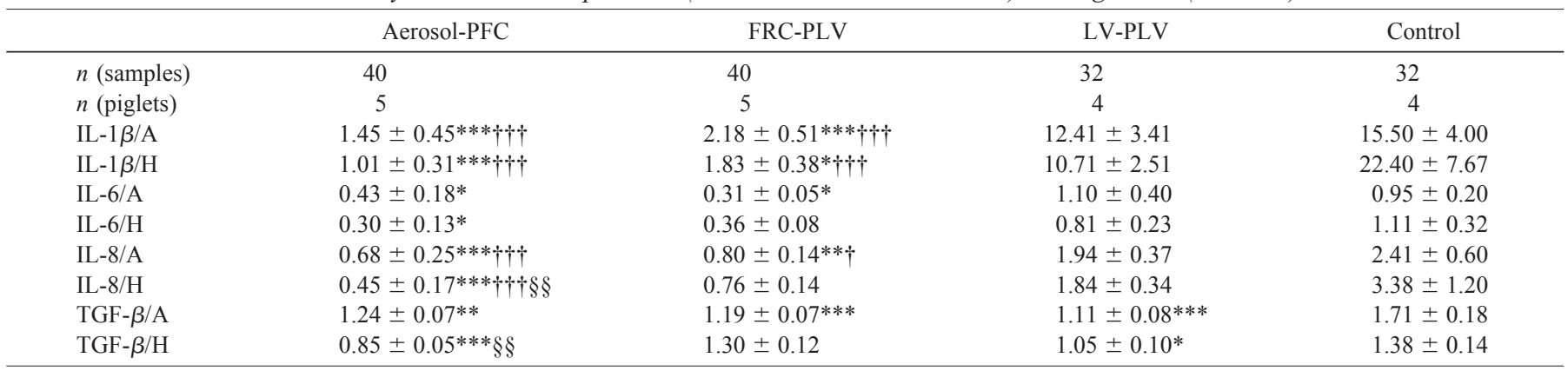

Four samples were obtained from the inferior lobe, two from the superior and two from the middle lobe. From each lobe, samples were taken from the anterior and posterior part.

$* p<0.05, * * p<0.01, * * * p<0.001$ compared with control.

$939 p<0.05, \dagger \dagger p<0.01, \dagger \dagger p<0.001$ compared with LV-PLV.

$\S p<0.05, \S \S p<0.01, \S \S \S p<0.001$ compared with FRC-PLV.

A

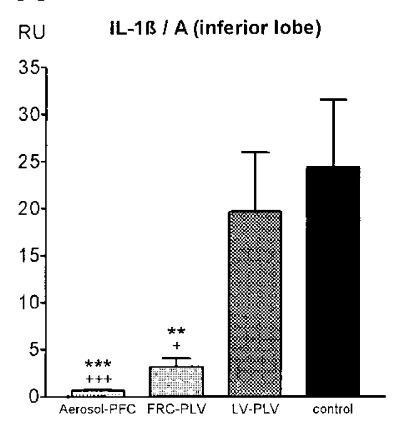

B

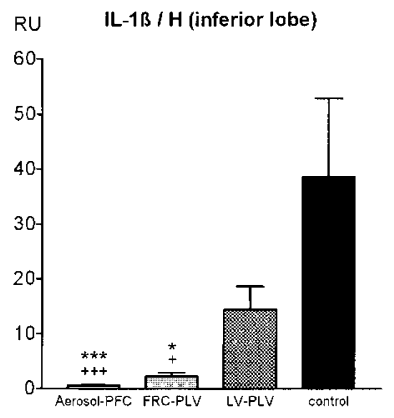

C

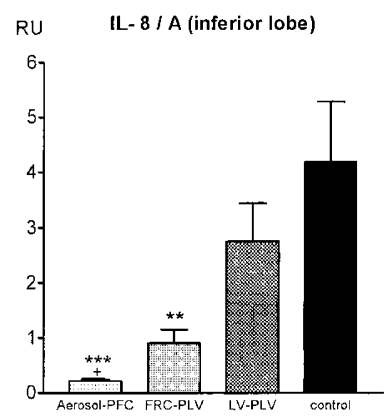

D

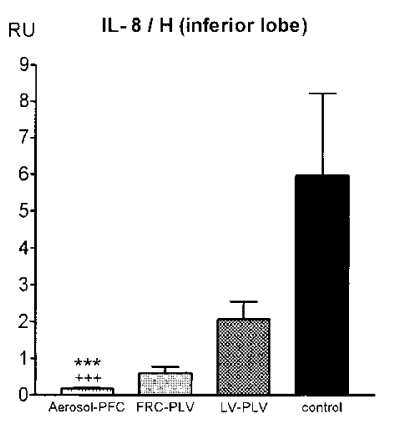

Figure 1. Pulmonary IL- $1 \beta / \beta$-actin mRNA expression $(A)$, IL- $1 \beta / \mathrm{HPRT}$ mRNA expression $(B)$, IL-8/ $\beta$-actin mRNA expression $(C)$, and IL-8/HPRT mRNA expression $(D)$ in the inferior lobe of the lung of surfactant depleted piglets after a therapy period of $2 \mathrm{~h}$ with either aerosolized PFC $(10 \mathrm{~mL} / \mathrm{kg} / \mathrm{h})$ (aerosol-PFC), PLV with FRC filling volume $(30 \mathrm{~mL} / \mathrm{kg}$ ) (FRC-PLV), lowvolume $(10 \mathrm{~mL} / \mathrm{kg} / \mathrm{h})$ PLV (LV-PLV) or IMV (control), and an observation period of 6 h. $R U$, relative units. ${ }^{*} p<0.05 ;{ }^{* *} p<0.01 ;{ }^{* * *} p<0.001$ compared with control; ${ }^{+} p<0.05 ;{ }^{+++} p<0.001$ compared with LV-PLV.

ever, in the control group, there was a tendency to higher gene expression of IL-1 $\beta$, IL- 6 , and IL- 8 in the inferior lobe compared with the superior lobe, which was seen to a lesser extent in the FRC-PLV and not in the aerosol-PFC group.

\section{DISCUSSION}

The present study investigated the early pulmonary inflammatory reaction in a surfactant-depleted piglet model using four different ventilation strategies and a quantitative mRNA

analysis. Because mRNA expression precedes protein formation, mRNA expression of early cytokines was quantified using TaqMan real-time PCR as a highly sensitive new approach (21, 22). Significant differences in mRNA expression of the proinflammatory cytokines IL- $1 \beta$, IL- 6 , and the chemokine IL-8 were observed after $8 \mathrm{~h}$, indicating the early onset of pulmonary inflammatory reaction. These data are in line with recent findings of reduced pulmonary neutrophil accumulation and myeloperoxidase activity and decreased oxidative damage to tissues, suggesting a decrease in overall inflammation by PLV as early as $4 \mathrm{~h}$ after lung injury in rabbits (16).

Comparison of the FRC-PLV to the control group showed a significantly lower mRNA expression of IL- $1 \beta$ when normalized to both housekeeping genes. When normalized only to $\beta$-actin, the reduction was also significant for IL-6, IL- 8 , and TGF- $\beta$. This may indicate an anti-inflammatory effect of FRCPLV, although conclusions have to be drawn with caution. The lack of significance for IL-6, IL-8, and TGF- $\beta$ when normalized to hypoxanthine-guanine-phosphoribosyl-transferase might be the result of the small number of piglets enrolled. These data are in line with the data of others (13), who found reduced protein concentrations of IL- $1 \beta$, IL-6, IL- 8 , and IL-10 in bronchoalveolar lavage (BAL) specimens of trauma patients receiving PLV (perfluorooctylbromide) at FRC volume after $1-4 \mathrm{~d}$. In a model of surfactant-depleted piglets, reduced BAL concentrations of IL-6, leukotriene B4, prostaglandin F1, thromboxane B2, and tumor necrosis factor- $\alpha$ were measured in a FRC-PLV group compared with a surfactant-treated IMV and high-frequency oscillation ventilation group $24 \mathrm{~h}$ after the induction of lung injury (23). Our data demonstrate an activation of the genes for various cytokines as early as $8 \mathrm{~h}$ after surfactant depletion. The reason for this could be-at least in part - the use of a highly sensitive technique for mRNA quantification and the fact that the rise in gene expression precedes protein formation. Relating the amount of mRNA to constitutively expressed mRNA is similar to the accepted approach of expressing protein levels in tissue per milligram of protein analyzed. This method of normalization was not performed in the BAL studies cited above.

Concerning the effectiveness of PFC doses lower than FRC, data in the literature are controversial (24-26). In our study, 
Table 2. Cytokine $m R N A$ expression (mean \pm SEM; relative units) in lung tissue (inferior lobe)

\begin{tabular}{|c|c|c|c|c|}
\hline & Aerosol-PFC & FRC-PLV & LV-PLV & Control \\
\hline$n$ (samples) & 20 & 20 & 16 & 16 \\
\hline$n$ (piglets) & 5 & 5 & 4 & 4 \\
\hline IL-6/A & $0.25 \pm 0.06$ & $0.40 \pm 0.19$ & $1.89 \pm 0.76$ & $1.23 \pm 0.28$ \\
\hline TGF- $\beta / \mathrm{A}$ & $1.30 \pm 0.11 *$ & $1.51 \pm 0.09$ & $1.44 \pm 0.08$ & $1.79 \pm 0.20$ \\
\hline TGF- $\beta / \mathrm{H}$ & $0.94 \pm 0.07$ & $1.46 \pm 0.21$ & $1.15 \pm 0.11$ & $1.56 \pm 0.25$ \\
\hline
\end{tabular}

Two probes each were obtained from the anterior and posterior part.

$* p<0.05, * * p<0.01, * * * p<0.001$ compared with control.

$\dagger p<0.05, \dagger \dagger p<0.01, \dagger \dagger \dagger p<0.001$ compared with LV-PLV.

$\S p<0.05, \S \S p<0.01, \S \S \S p<0.001$ compared with FRC-PLV.

Table 3. Cytokine $m R N A$ expression (mean $\pm S E M$; relative units) in lung tissue (middle lobe)

\begin{tabular}{lcccc}
\hline & Aerosol-PFC & FRC-PLV & LV-PLV & Control \\
\hline$n$ (samples) & 20 & 20 & 16 & 4 \\
$n$ (piglets) & 5 & 5 & $6.44 \pm 2.49$ & 4 \\
IL-1 $\beta / A$ & $2.92 \pm 1.36$ & $1.31 \pm 0.46^{*} \dagger$ & $9.31 \pm 4.81$ & $10.02 \pm 3.90$ \\
IL-1 $\beta / H$ & $1.96 \pm 0.94$ & $0.39 \pm 0.49$ & $0.33 \pm 0.11$ & $9.46 \pm 4.50$ \\
IL-6/A & $0.96 \pm 0.58$ & $0.45 \pm 0.16$ & $0.47 \pm 0.23$ & $1.07 \pm 0.51$ \\
IL-6/H & $0.61 \pm 0.40$ & $0.74 \pm 0.22$ & $1.41 \pm 0.44$ & $0.86 \pm 0.40$ \\
IL-8/A & $1.51 \pm 0.78$ & $0.89 \pm 0.35$ & $1.79 \pm 0.79$ & $1.10 \pm 0.39$ \\
IL-8/H & $1.00 \pm 0.53$ & $0.86 \pm 0.08$ & $0.77 \pm 0.10$ & $1.07 \pm 0.38$ \\
TGF- $\beta$ /A & $1.28 \pm 0.14 \dagger \S$ & $1.07 \pm 0.17$ & $0.92 \pm 0.29$ & $1.31 \pm 0.63$ \\
TGF- $\beta$ /H & $0.90 \pm 0.13$ & & & \\
\hline
\end{tabular}

Two probes each were obtained from the anterior and posterior part.

$* p<0.05, * * p<0.01, * * * p<0.001$ compared with IMV.

$\dagger p<0.05, \dagger \dagger p<0.01, \dagger \dagger \uparrow p<0.001$ compared with LV-PLV.

$\S p<0.05, \S \S p<0.01, \S \S \S p<0.001$ compared with FRC-PLV.

Table 4. Cytokine mRNA expression (relative units) in lung tissue (superior lobe)

\begin{tabular}{llccc}
\hline & Aerosol-PFC & FRC-PLV & LV-PLV & Control \\
\hline$n$ (samples) & 20 & 20 & 16 & 4 \\
$n$ (piglets) & 5 & 5 & $3.79 \pm 1.18$ & 4 \\
IL-1 $\beta /$ A & $0.95 \pm 0.37 \dagger$ & $1.39 \pm 0.39 \dagger$ & $4.76 \pm 1.58$ & $3.17 \pm 1.54$ \\
IL-1 $\beta$ /H & $0.62 \pm 0.23 \dagger \dagger$ & $0.40 \pm 0.09$ & $0.30 \pm 0.09$ & $2.89 \pm 1.60$ \\
IL-6/A & $0.20 \pm 0.05$ & $0.62 \pm 0.19$ & $0.38 \pm 0.12$ & $0.30 \pm 0.13$ \\
IL-6/H & $0.12 \pm 0.03 \dagger \S$ & $0.68 \pm 0.18$ & $1.09 \pm 0.35$ & $0.24 \pm 0.11$ \\
IL-8/A & $0.40 \pm 0.12 \dagger$ & $0.91 \pm 0.29$ & $1.44 \pm 0.57$ & $0.66 \pm 0.18$ \\
IL-8/H & $0.25 \pm 0.07 \dagger \S$ & $0.88 \pm 0.08^{* * *}$ & $0.79 \pm 0.12^{* * *}$ & $0.50 \pm 0.12$ \\
TGF- $\beta$ /A & $0.91 \pm 0.10^{* * *}$ & $1.23 \pm 0.18$ & $0.95 \pm 0.19$ & $1.42 \pm 0.06$ \\
TGF- $\beta$ /H & $0.62 \pm 0.07^{* *} \S \S$ & & & $1.10 \pm 0.16$ \\
\hline
\end{tabular}

Two probes each were obtained from the anterior and posterior part.

${ }^{*} p<0.05, * * p<0.01, * * * p<0.001$ compared with IMV.

$\dagger p<0.05, \dagger \dagger p<0.01, \dagger \dagger p<0.001$ compared with LV-PLV.

$\S p<0.05, \S \S p<0.01, \S \S \S p<0.001$ compared with FRC-PLV.

PLV with FC77 at low volume $(10 \mathrm{~mL} / \mathrm{kg} / \mathrm{h})$ could provide neither an anti-inflammatory effect nor a significant improvement in gas exchange or lung mechanics.

FRC-PLV led to a significant reduction of cytokine mRNA expression and improvement of gas exchange and lung mechanics. Tensio-active properties of PFC may ease the closing/ reopening forces in FRC-PLV, reducing barotrauma. However, filling the lung up to FRC leaves only a small lung volume to gas ventilation, promoting overstretch of the lung structures inducing an inflammatory response in liquid-free compartments. The risk of overstretch was reduced in our study by using pressure controlled ventilation. As we could demonstrate a significant reduction of proinflammatory cytokine mRNA expression in the FRC-PLV but not in the LV-PLV group, a high PFC lung surface contact may be an important factor for the anti-inflammatory effect.
PFC at a dose of $10 \mathrm{~mL} / \mathrm{kg} / \mathrm{h}$ was highly effective when applied as aerosol. A significant reduction of the mRNA expression of IL- $1 \beta$, IL-6, IL-8, and TGF- $\beta$ compared with the control group indicates a potential for suppression of acute pulmonary inflammation. Compared with the low-volume group, mRNA expression of IL- $1 \beta$ and IL- 8 was significantly lower in the aerosol-PFC group. This effect was most pronounced in the inferior lobe. The reduction of cytokine mRNA expression was even more pronounced by application of aerosol than by conventional PLV (FRC-PLV group). Our data indicate that the method of PFC application (e.g. as aerosol) influences the effectiveness of therapy with PFC. Because of its high specific weight, liquid PFC will be distributed by gravity predominantly to the dependent pulmonary regions (27). Administration as an aerosol may lead to a more homogenous intrapulmonary distribution of oxygenated small-sized PFC 
particles, being distributed with the inspiratory gas stream. So far, no data exist on intrapulmonary distribution of aerosolized PFC. Future studies will investigate this question. Intensive lung surface contact with PFC through exposure of the bronchi and airways to respiratory gas with aerosolized FC77 might enhance the beneficial effects of PFC and may be the reason for improved gas exchange, lung mechanics, and reduced pulmonary inflammation in comparison to both the control and the LV-PLV group.

The exact mechanisms of the reduction of inflammatory response cannot be elucidated so far by our experimental approach. As oxygenation, gas exchange, and dynamic compliance improved significantly in the aerosol-PFC group (28), one might anticipate reduced mechanical trauma. Hypoxia might have enhanced the inflammatory process in the IMV and LV-PLV group (28). Our data do not define the proportional contribution of lung lavage and mechanical ventilation to the induction of lung injury, as no nonlavaged but ventilated control group was included.

Especially in the control group, cytokine mRNA expression was more pronounced in the inferior lobe than in any other lobe, but the data were not significant. This corresponds to the severe atelectasis found predominantly in the dependent lung areas in ARDS patients and to histologic data in animal studies $(10,12)$. With PFC treatment, the reduction of cytokine mRNA expression tended to be more pronounced in the inferior lobe. However, the comparison of cytokine mRNA expression in the superior, middle, and inferior lobe within each therapy group revealed no significant difference. The lack of significant differences in cytokine mRNA expression between the dependent and nondependent pulmonary regions with a tendency for higher mRNA expression in the dependent pulmonary regions in the control and FRC-PLV group and for lower mRNA expression in the aerosol-PFC group might be a consequence of the small number of animals, the short observation period, and also the small size of the piglets, leveling hydrostatic pressure differences. Although not significant, the reduction in difference between cytokine mRNA expression between dependent and nondependent lung areas in FRC-PLV additionally indicates that our data are not in contrast to data in literature. Differences in regional lung injury were shown in PLV, e.g. a reduction of lung injury score in the dependent pulmonary areas compared with conventional ventilation (12) and a higher lung injury score in the dependent pulmonary areas than in the nondependent pulmonary areas within the PLV-treated group (10).

In summary, increased mRNA expression of proinflammatory cytokines in porcine lung tissue was detected as early as $8 \mathrm{~h}$ after establishment of lung injury following surfactant depletion. Therapy with aerosolized PFC (FC77) and-to a lesser degree - with FC77 at FRC volume resulted in a significantly lower mRNA expression of proinflammatory cytokines compared with therapy with IMV and/or low-dose FC77 in our model.

Acknowledgments. The authors thank Sophie Brüggemeier and Julia Walther for excellent technical assistance.

\section{REFERENCES}

1. Speer CP 1999 Inflammatory mechanisms in neonatal chronic lung disease. Eur J Pediatr 158(suppl 1):18-22

2. Özdemir A, Brown MA, Morgan WJ 1997 Markers and mediators of inflammation in neonatal lung disease. Pediatr Pulmonol 23:292-306

3. Ogawa Y, Miyasaka, Kawano T, Imura S, Inukai K, Okuyama K, Oguchi K, Togari H, Nishida H, Mishina J 1993 A multicenter randomized trial of high frequency oscillatory ventilation as compared with conventional mechanical ventilation in preterm infants with respiratory failure. Early Hum Dev 32:1-10

4. Clark RH, Gerstmann DR, Null DM, deLemos RA 1992 Prospective randomized comparison of high frequency oscillatory and conventional ventilation in respiratory distress syndrome. Pediatrics 89:5-12

5. Gerstmann DR, Minton SD, Stoddard RA, Meredith KS, Monaco F, Bertrand JM, Battisti O, Langhendries JP, Francois A, Clark RH 1996 The Provo multicenter early high-frequency oscillatory ventilation trial: improved pulmonary and clinical outcome in respiratory distress syndrome. Pediatrics 98:1044-1057

6. Demirakça S, Dötsch J, Knothe C, Magsaam J, Reiter HL Bauer J, Kuehl PG 1996 Inhaled nitric oxide in neonatal and pediatric acute respiratory distress syndrome. Dose response, prolonged inhalation and weaning. Crit Care Med 24:1913-1919

7. Houmes RJM, Verbrugge SJC, Hendrik ER, Lachmann B 1995 Hemodynamic effects of partial liquid ventilation with perfluorocarbon in acute lung injury. Intensive Care Med 21:966-972

8. Lowe Leach C, Fuhrmann B, Morin III FC, Rath MG 1993 Perfluorocarbonassociated gas exchange (partial liquid ventilation) in respiratory distress syndrome: a prospective, randomized, controlled study. Crit Care Med 21:1270-1278

9. Overbeck MC, Pranikoff T, Yadao CM, Hirschl RB 1996 Efficacy of perfluorocarbon partial liquid ventilation in a large animal model of acute respiratory failure. Crit Care Med 24:1208-1214

10. Quintel M, Heine M, Hirschl RB, Tillmanns R, Wessendorf V 1998 Effects of partial liquid ventilation on lung injury in a model of acute respiratory failure: A histologic and morphometric analysis. Crit Care Med 26:833-843

11. Shaffer TH, Wolfson MR, Clark LC Jr 1992 Liquid ventilation. Pediatr Pulmonol 14:102-109

12. Rotta AT, Gunnarsson B, Hernan LJ, Fuhrman BP, Steinhorn DM 1999 Partial liquid ventilation influences pulmonary histopathology in an animal model of acute lung injury. J Crit Care 14:84-92

13. Croce MA, Fabian TC, Patton JH Jr, Melton SM, Moore M, Trenthem LL 1998 Partial liquid ventilation decreases the inflammatory response in the alveolar environment of trauma patients. J Trauma 45:273-282

14. Leach CL, Greenspan JS, Rubenstein SD, Shaffer TH, Wolfson MR, Jackson JC, DeLemos R, Fuhrman BP 1996 Partial liquid ventilation with perflubron in premature infants with severe respiratory distress syndrome. The LiquiVent Study Group. N Engl J Med 335:761-767

15. Alliance Pharmaceutical Corp 2001 Preliminary results of LiquiVent ${ }^{\circledR}$ Phase $2-3$ Clinical Study. Presented at the Annual Meeting of the American Thoracic Society, San Francisco, May 2001

16. Rotta AT, Steinhorn DM 1998 Partial liquid ventilation reduces pulmonary neutrophil accumulation in an experimental model of systemic endotoxemia and acute lung injury. Crit Care Med 26:1707-1715

17. Colton DM, Till GO, Johnson KJ, Dean SB, Barlett RH, Hirschl RB 1998 Neutrophil accumulation is reduced during partial liquid ventilation. Crit Care Med 26:17161724

18. Smith TM, Steinhorn DM, Thusu K, Fuhrmann BP, Dandona P 1995 A liquid perfluorochemical decreases the in vitro production of reactive oxygen species by alveolar macrophages. Crit Care Med 23:1533-1539

19. Lachmann B, Robertson B, Vogel J 1980 In vivo lung lavage as an experimental model of the respiratory distress syndrome. Acta Anaesth Scand 24:231-236

20. MacIntyre N, Andjuval S, Baran G 1996 Aerosol deposition from an intra-airway aerosol. Eur Respir J 9(suppl 23):P0396

21. Dötsch J, Nüsken KD, Knerr I, Kirschbaum M, Repp R, Rascher W 1999 Leptin and neuropeptide Y gene-expression in human placenta: ontogeny and evidence for similarities to hypothalamic regulation. J Clin Endocrinol Metab 84:2755-2758

22. Heid CA, Stevens J, Livak KJ, Williams PM 1996 Real time quantitative PCR. Genome Res 6:986-994

23. Merz U, Kellinghaus M, Klosterhalfen B, Peschgens TH, Kurth A, Hörnchen H 2000 Inflammatory mediators in bronchioalveolar lavage after partial liquid ventilation (PLV) in surfactant-depleted newborn pigs. Eur J Med Res 5:78

24. Wolfson MR, Kechner NE, Roache RF, DeChadarevian JP, Friss HE, Rubenstein SD, Shaffer TH 1998 Perfluorochemical rescue after surfactant treatment: effect of perflubron dose and ventilatory frequency. J Appl Physiol 84:624-40

25. Cannon ML, Cheifetz IM, Craig DM, Hubble CL, Quick G, Ungerleider RM, Smith PK, Meliones JN 1999 Optimizing liquid ventilation as a lung protection strategy for neonatal cardiopulmonary bypass: full functional residual capacity dosing is more effective than half functional residual capacity dosing. Crit Care Med 27:1140-1146

26. Lim CM, Koh Y, Jung BO, Lee SD, Kim WS, Kim DS, Kim WD 2000 An optimal dose for respiratory mechanics in partial liquid ventilation for dependent lungdominant acute lung injury. Chest 117:199-204

27. Quintel M, Hirschl RB, Roth H, Loose R, van Ackern K 1998 Computer tomographic assessment of perfluorocarbon and gas distribution during partial liquid ventilation for acute respiratory failure. Am J Resp Crit Care Med 158:249-255

28. Kandler MA, von der Hardt K, Schoof E, Dötsch J, Rascher W 2001 Persistent improvement of gas exchange and lung mechanics by aerosolized perfluorocarbon. Am J Resp Crit Care Med 164:31-35 